\title{
Geopolítica del agua en Colombia: la seguridad humana frente a los intereses transnacionales
}

\section{Geopolitics of water in Colombia: \\ Human security against transnational interests}

\author{
José Luis Cadena Montenegro*
}

Artículo de revisión

Cómo citar este artículo: Cadena Montenegro, J.L. (2011). Geopolítica del agua en Colombia: la seguridad humana frente a los intereses transnacionales. Revista CIFE, 13 (19), 127-150.

\section{Resumen}

El desarrollo de los pueblos a través de los tiempos ha dependido de los cambios políticos, económicos, culturales y de la tecnología disponible para realizar las obras de infraestructura que posibiliten el mejoramiento de las condiciones de vida de los ciudadanos. No siempre los modelos empleados en América Latina para lograr el desarrollo, han obedecido a decisiones racionales basadas en análisis científicos; en algunos casos, intereses personalistas de gobernantes incapaces promovieron su aplicación improvisada y su efecto ha sido negativo por ser importados desde otras latitudes en las que se constituyeron en paradigmas de otros tiempos. La solución de problemas que afectan a la población es función de los Estados; en especial, los relacionados con servicios públicos que permitan mejorar la calidad de vida. Los recursos naturales han pasado a ser en el nuevo siglo los productos más

* Geógrafo y Politólogo colombiano, Profesional en Ciencias Militares; Magíster en Ciencia Política, Universidad de los Andes; Magíster en Planeación Socioeconómica, Universidad Santo Tomás; Magíster en Geografía y Ordenamiento Territorial, convenio UPTC-IGAC. Doctor en Geografía, Universidad Nacional Autónoma de México, especialidad en Geopolítica. Ex presidente de la Asociación Colombiana de Geógrafos (ACOGE), Miembro de la Asociación Americana de Geógrafos (AAG), Miembro del Instituto de Política y Democracia, Brasil; Catedrático de la Universidad Santo Tomás, Director del Grupo de Investigación en Geopolítica y Relaciones Internacionales. Consultor internacional en defensa y seguridad. Correo electrónico: jlcadenam@yahoo.com 
valiosos para continuar en la carrera del desarrollo tecnológico, supuestamente con la intención de buscar el bien común del que habló Tomás de Aquino. En nuestros tiempos, el fenómeno de la aculturación juega un importante papel cuando de abrir nuevos espacios económicos se trata. En el nuevo siglo, la seguridad humana pretende poner al hombre en el centro del interés global. Este ensayo es parte de una investigación de alcance mayor en desarrollo.

Palabras clave: seguridad humana, geopolítica, políticas públicas, desarrollo.

Clasificación JEL: H55, H57, J23, O 10.

\section{Abstract}

The development of the communities through the ages has depended on the political, economical, cultural and technological changes available for infrastructure projects that facilitate the improvement of living conditions for

1 El bien común no es solo un conjunto de ventajas y utilidades, sino rectitud de vida, algo éticamente bueno. "Lo que constituye el bien común de la sociedad política, no es solamente el conjunto de bienes y servicios de utilidad pública o de interés nacional (caminos, puertos, escuelas, etc.), ni las buenas finanzas del Estado, ni su pujanza militar. (...) No es solamente el conjunto de leyes justas, de buenas costumbres y de instituciones sabias que dan su estructura a la nación, ni la herencia de los gloriosos recuerdos históricos, de sus símbolos y de sus glorias, de sus tradiciones y de sus tesoros de cultura. (...) El bien común comprende sin duda, todas esas cosas, pero con más razón otras muchas: algo más profundo, más concreto y más humano. (...) El bien común no es solamente un conjunto de ventajas y de utilidades, sino rectitud de vida, fin bueno en sí, al que los antiguos llamaban bonum honestum, bien honesto". the citizens. Models applied in Latin America to achieve development have not always been due to rational decisions based on scientific analysis; in some situations, personal interests of inexperienced governments promoted their improvised implementation and their effects have been negative because these models have been imported from elsewhere. Solving the problems that affect the population is a matter of the states, specially the problems related with utilities that will allow to improve the life quality. Natural resources have become in this new century, the most valuable products to pursue the race for technological development, presumably with the intention of seeking the common good as Tomas de Aquino said. In the new century, human security seeks to establish the human being as the center of global interest.

Keywords: Human security, geopolitics, public policy, development.

Classification JEL: H55, H57, J23, O10.

\section{Introducción}

La situación de alarma generalizada que se vive actualmente con relación al suministro de agua potable, aunque se trate de una angustia cotidiana que paradójicamente se ha normalizado como parte del orden mundial, no puede hacernos olvidar que 1.800 millones de personas, de las cuales el $80 \%$ habita en ambientes rurales, no tienen acceso a un sistema de agua tratada que les garantice, al menos, 20 litros al día y que 2.000 millones de seres humanos no disponen de ningún tipo de saneamiento. Estas cifras configuran un siniestro escenario ante 
la confirmación de que cada año aproximadamente unos 2.000 millones de personas contraen algún tipo de enfermedad cuya causa está relacionada con la carencia y calidad del agua ${ }^{2}$.

Desde el punto de vista de la erradicación de la pobreza, objetivo central de la agenda internacional para el desarrollo, resolver las carencias que con relación al agua existen en amplias regiones del mundo, es un problema de trascendental importancia dados los efectos colaterales que tiene sobre otros aspectos críticos que contribuyen a su reducción. Por contradictorio que parezca, en el siglo XXI el derecho al agua no existe como un auténtico y expreso Derecho Humano Universal. La Declaración Universal de Derechos Humanos de 1948 no lo incluyó explícitamente en el artículo 25 de su texto por ser tan obvio en razón de su naturaleza que a sus redactores, les pareció innecesario, lo mismo que el derecho al aire.

Estamos hablando de dos bienes públicos puros, es decir, de los que nadie puede abstraerse.

La Declaración Ministerial de La Haya, adoptada en el segundo Forum Mundial del Agua, celebrado el 22 de marzo de 2000, reconoció que "el acceso seguro y suficiente al agua potable y de saneamiento son necesidades humanas básicas y son esenciales para la salud y el bienestar". No se imaginaron los declarantes de La Haya que el agua ya estaba inmersa en las agendas de las empresas transnacionales que convirtieron la geopolítica en geoeconomía.

El Estado, en su rol de garante del goce y ejercicio pleno de los derechos de los ciudadanos bajo su jurisdicción,

2 Estas y otras cifras que se citan en este ensayo, se encuentran en United Nations Development Programme (UNDP). Human Development Report 2006. Beyond scarcity; power, poverty and the global water crisis. debe asegurar el acceso al agua potable por parte de todos, sin distinciones de ningún tipo; de igual manera, debe comprometerse a vigilar el buen estado del recurso hídrico en su territorio, y abstenerse de realizar actividades nocivas que vayan en detrimento del mismo. También corresponde al Estado, en sus diferentes órbitas o niveles de actuación, hacer expeditas las vías de reclamo frente a violaciones de derechos humanos que se originen, entre otros motivos, en la negación del acceso al agua potable, o la insuficiente provisión. El tema de los servicios públicos es pertinente a la economía social por tratarse de un bien sin el cual es imposible vivir.

La Organización de Naciones Unidas (ONU) aprobó el 28 de julio de 2010 el proyecto de resolución presentado por Bolivia para que el agua y el saneamiento sean declarados un derecho humano. A partir de la decisión de la Asamblea, los estados miembros de la ONU deben asumir políticas para dotar de los dos servicios a las poblaciones que no los tengan. La iniciativa boliviana recibió el respaldo de 122 países, más de dos tercios de los presentes en la Asamblea, y ningún voto en contra, a pesar de que 41 países se abstuvieron, lo que impidió que la medida fuera adoptada por unanimidad.

La "seguridad humana" se basa en el entendimiento fundamental de que los gobiernos tienen la función primordial de asegurar la supervivencia, los medios de vida y la dignidad de sus ciudadanos. Es un instrumento inestimable para ayudar a los gobiernos a determinar amenazas graves y generalizadas al bienestar de su población y la estabilidad de su soberanía; promueve programas y políticas para hacer frente a las nuevas amenazas y responde a ellas en forma pertinente y priorizada. Esto ayuda a los gobiernos y a la comunidad internacional a utilizar mejor sus recursos y elaborar estrategias que fortalezcan el marco de protección y empoderamiento necesario para la seguridad humana y la promoción de la paz y la 
estabilidad en todos los niveles: local, nacional, regional e internacional.

La Cumbre Mundial de 2005 y la decisión de la Asamblea General de la ONU de definir en mayor detalle el concepto de seguridad humana, han sido fundamentales para divulgar el mismo y despertar el interés al respecto. En el párrafo 143 del documento final de la Cumbre Mundial de 2005, los jefes de Estado y de gobierno reconocieron que "todas las personas, en particular las que son vulnerables, tienen derecho a vivir libres del temor y la miseria, a disponer de iguales oportunidades para disfrutar de todos sus derechos y a desarrollar plenamente su potencial humano". A tal efecto, los estados miembros de las Naciones Unidas convinieron examinar más a fondo el concepto de seguridad humana, el cual, con los aportes de varios gobiernos, así como de organizaciones intergubernamentales, grupos de la sociedad civil, académicos y otras personas expertas, está adquiriendo amplio apoyo en la ONU y otros foros.

El acceso deficiente al agua potable se ha convertido en la segunda causa de muerte infantil del planeta. Aunque, dada la magnitud, sea ya imposible interiorizarlo en términos emocionales, a pocas personas les puede interesar la noticia de que alrededor de 1.8 millones de niños mueren al año como consecuencia de graves problemas de salud derivados del consumo de agua insalubre. Esta suma es equivalente a la defunción diaria de la población de menores de 5 años de Nueva York y Londres sumadas, esto es, unos 4.900 niños fallecen cada 24 horas. Colombia, uno de los países más ricos en este recurso, es parte de este grave problema y la solución no parece de corto plazo.

$\mathrm{Al}$ consultar documentos sobre temas ambientales relacionados con la sostenibilidad, es posible advertir que, desde hace cierto tiempo, la expresión seguridad humana aparece con mayor frecuencia. Seguramente se debe a que la ONU ha empleado el término para designar un concepto muy importante desde finales de la última década del siglo XX.

Este ensayo, consecuentemente, pretende contribuir a la formación educativa ambiental y al conocimiento de la temática vinculada con el desarrollo humano y el desarrollo sostenible, dilucidando algunas de las principales connotaciones y aspectos relacionados con el concepto de seguridad humana, en particular, con relación a su aplicación en Latinoamérica y concretamente en Colombia. Para la ONU “...la seguridad humana es un proceso por el que se crean las condiciones de la dignidad del ser humano"3.

$\mathrm{Al}$ comenzar la segunda década del siglo XXI, los seres humanos no están en situación de riesgo solamente cuando son amenazados con armas letales; lo pueden estar en aquellas ocasiones en que padecen hambre o enfermedades, o cuando, por diversas circunstancias, se ponen en riesgo aspectos primordiales de su vida cotidiana y su espacio vital, entendiendo que este es el mínimo geográfico requerido para su supervivencia. Entre estas contingencias relacionadas con su existencia podemos mencionar la violación de los derechos humanos y de los principios democráticos, violencia, conflictos, terrorismo, cambio climático, deterioro ambiental y contamina-

3 El informe del Secretario General de las Naciones Unidas durante el sexagésimo cuarto período de sesiones, Temas 48 y 114 del programa aplicación y seguimiento integrados y coordinados de los resultados de las grandes conferencias y cumbres de las Naciones Unidas en las esferas económica y social y esferas conexas, seguimiento de los resultados de la Cumbre del Milenio, se refirió a la seguridad humana y fue distribuido el 8 de marzo de 2010. Este informe se presentó en cumplimiento del párrafo 143 del documento final de la Cumbre Mundial 2005 (resolución 60/1 de la Asamblea General), en el que los jefes de Estado y de gobierno se comprometieron a examinar y definir el concepto de seguridad humana. 
ción de la atmósfera (Sloterdijst, 2003) ${ }^{4}$, la hidrosfera y la litosfera. Pero también se pueden mencionar otras como la carencia de alimentos aptos y necesarios, enfermedades y epidemias, desempleo, migración forzada, inseguridad laboral, pobreza, analfabetismo, falta de vivienda y catástrofes naturales y antrópicas.

La seguridad humana debe entenderse, según la ONU, como una condición o situación que supone un cambio de perspectivas u orientación, y en la que se valore al mundo tomando como núcleo de referencia a las personas, más allá de consideraciones relacionadas con la seguridad estatal. Se trata de una idea-fuerza multiforme, aplicable en diversos contextos sociales, que asocia e incluye diferentes condiciones para el pleno desarrollo humano (Pereira, 2011).

Según este novedoso concepto interdisciplinario, la seguridad se fundamenta primordialmente en la promoción y protección de los derechos de la ciudadanía, que garantizan el bienestar y la satisfacción de las personas en el marco de la propia sociedad, más que en el esquema convencional de fortalecimiento del Estado y la defensa armada de sus instituciones ante posibles amenazas, intimidaciones o asechanzas internas o externas.

En efecto, quienes impulsan en los tiempos actuales acciones relacionadas con la seguridad humana se preocupan prioritariamente por la seguridad de los individuos y las comunidades, en principio en lo que refiere a la lucha contra el hambre, la pobreza, epidemias, desastres naturales, violencia y situaciones similares. Por tanto, la seguridad humana implica proporcionar a las personas

4 Peter Sloterdijst en su libro Temblores de Aire, denomina atmoterrorismo el envenenamiento de la atmósfera con fines bélicos. Hoy se aplica el término para mencionar las acciones antrópicas que mediante el empleo de gases venenosos, controlan manifestaciones públicas o los emplean en la lucha antiterrorista. seguridad contra amenazas u obstáculos violentos y no violentos. Obviamente, el concepto es muy amplio, complejo y general, debido a que las instituciones internacionales y nacionales, y los gobiernos, han abordado este tema desde diferentes perspectivas:

Se puede asegurar que la seguridad humana conlleva a un cambio drástico entre el enfoque tradicional de seguridad que implica una reforma compleja y dramática en la conceptualización de seguridad desde un nuevo modelo analítico y político de corte multidimensional y con numerosas visiones de la realidad internacional ${ }^{5}$.

Los países del Tercer Mundo son los más necesitados de la aplicación de este nuevo concepto.

Organizaciones y personas comprometidas con el tema de la seguridad humana suelen citar como su objetivo primordial, aquel que apunta a la expectativa de "salvaguardar las vidas humanas de las amenazas críticas dominantes y es consistente, en cierto modo, con la realización de las personas en el largo plazo". En algunos casos, la seguridad humana es definida también como "seguridad centrada en las personas", o "seguridad con un rostro humano", porque, conforme a lo mencionado, posiciona prioritariamente a las personas en el punto central del escenario de la seguridad. Al mismo tiempo, el concepto pone énfasis en la permanencia de los logros. Es decir, además de asegurar a todos la posibilidad de acceder a las condiciones sociales y económicas fundamentales, pretende también consolidar la persistencia y sostenibilidad de ese acceso.

5 Para mayor información, consultar a Ortiz Navarrete, Jonathan. La doctrina de la seguridad humana en la política exterior canadiense. La contribución de Lloyd Axworthy al estudio de la política mundial. Revista Cidofb d'afers internacionals, 60; diciembre 2002 - enero 2003. 
En diferentes eventos y en razón a que la seguridad humana resalta aspectos comunes y nexos entre los derechos humanos y el desarrollo de la sociedad, el concepto ha sido incorporado a importantes debates y acuerdos sobre asuntos ambientales, particularmente vinculados con la sostenibilidad y el desarrollo sostenible. Conviene destacar también que, ante la significación de esta ideafuerza, la ONU estableció a partir de 2004 una Unidad de Seguridad Humana en su Oficina de Coordinación de Asuntos Humanitarios.

\section{2. Áreas básicas de la seguridad humana}

Para una mejor comprensión y aproximación a su logro, la seguridad humana suele desglosarse en varias áreas básicas de pertinencia y compromiso que, por supuesto, están fuertemente interrelacionadas $(\mathrm{ONU})^{6}$. Entre estas se consideran como relevantes la seguridad ambiental, seguridad científica y tecnológica, seguridad cultural, seguridad económica y financiera, seguridad en función de igualdad de género, seguridad jurídica y seguridad social. Se han reconocido ciertas condiciones mínimas, cuya vigencia resulta indispensable para poder encaminarse al logro de la seguridad humana.

Una vez procuradas las condiciones básicas pueden conseguirse otras de nivel intermedio que, a su vez, conducen a alcanzar el objetivo final que propone el concepto. Entre las condiciones básicas se encuentran el acceso al empleo, a la infraestructura, a los bienes y servicios sociales, a la seguridad alimentaria, a la protección integral

6 Departamento de Información Pública de las Naciones Unidas. Preparada en español por la Sección del Sitio Internet de la ONU de la División de Noticias y Medios de Información del Departamento de Información Pública (ONU, 2002). de las personas y a un entorno apropiado que promueva una mejor calidad de vida.

Las condiciones de nivel intermedio son aquellas cuya consecución, después del logro de las condiciones básicas, conducen al bienestar, la comodidad, la dignidad, el decoro y la certeza de la vida de las personas. Se puede afirmar entonces que el objetivo final de la seguridad humana consiste en alcanzar la situación de armonía social que abarca el respeto, la cooperación, la solidaridad y el afecto entre las personas. Surgen entonces los obstáculos o amenazas al logro de la seguridad humana y son precisamente aquellos eventos, acciones u omisiones que podrían oponerse a alcanzar las condiciones básicas, entre los que se encuentran el desempleo, las bajas remuneraciones, las inequidades, los conflictos, la prestación o suministro deficiente de los servicios básicos como educación, salud, agua potable, alcantarillado, vías, la degradación de los recursos naturales, y otros no menos importantes. En los siguientes párrafos y de manera resumida, trataremos los tradicionales conceptos de seguridad y señalaremos la importancia de los temas particulares a los que hace referencia la seguridad humana, de manera que se pueda reconocer las diferencias.

La seguridad nacional es la situación en la que un Estado se considera resguardado contra agresiones militares, presiones políticas o coerciones económicas significativas, para obtener con ello libertad de acción que le permita proseguir con su propio desarrollo y progreso (ONU, 1986), consolidándose así el sector de la defensa. La seguridad nacional es, en otras palabras, la suma de actividades que tienen por objeto preservar los intereses vitales de la nación, es decir, aquellos que se encuentran consagrados en la Constitución Política. En tanto que el principal instrumento coercitivo que detenta el Estado para hacer frente a las amenazas a la seguridad nacional son sus Fuerzas Militares, que en Colombia, son el 
Ejército, la Armada y Fuerza Aérea, que junto con la Policía Nacional, reciben la denominación de Fuerzas Armadas.

Como en otros ámbitos, el proceso de globalización ha tenido también su impacto sobre el sector defensa. De esta manera, los diferentes planes nacionales identifican las denominadas "amenazas modernas a la seguridad nacional" que, de acuerdo con los efectos geopolíticos, son el narcotráfico, el lavado de dinero, el tráfico ilegal de armas, las migraciones forzadas, la delincuencia organizada y el terrorismo, entre otros.

La seguridad interior es la situación de un orden nacional en que los poderes públicos son respetados como instituciones, al igual que las personas que los encarnan, con la adecuada defensa del régimen, de los derechos fundamentales de los ciudadanos, de la paz social y la tranquilidad pública. La rebelión, la sedición, los desórdenes públicos, los atentados y desacatos contra la autoridad configuran, entre otros, el repertorio penal de las manifestaciones hostiles a esta clara atmósfera civil (Cabanellas, 1986).

La misma se concibe como una categoría intermedia entre la seguridad nacional y la seguridad pública, que en algunos países se define como situación de conmoción interior e inestabilidad social y que, aunque preocupante, no reviste todavía la gravedad como para ser considerada una amenaza a los intereses permanentes de la nación. Tratándose de los países centrales, el Estado cuenta con las denominadas fuerzas de seguridad (especie de policía militarizada) para enfrentar y neutralizar fenómenos que rebasan la capacidad preventiva y reactiva de las fuerzas policiales.

En los países periféricos, generalmente estas funciones las han cumplido las fuerzas militares, en contravía con la teoría sobre el uso de la violencia estatal, y han permitido incluso la violación de los derechos de los ciudadanos. Es obvio que este tipo de funciones son de responsabilidad de la policía y organismos especializados en su apoyo.

La seguridad pública es una función a cargo del Estado que tiene como fin primordial salvaguardar y preservar las libertades y la paz pública. Su mayor esfuerzo se orienta a proteger y respetar la vida, la integridad corporal, la dignidad y los derechos de las personas así como de sus bienes, mantener el orden y la tranquilidad, velar por el cumplimiento de las leyes, reglamentos y disposiciones administrativas vigentes, promover y coordinar los programas de prevención de delitos e infracciones a las leyes y reglamentos, combatir las causas que generan la comisión de delitos y conductas antisociales, y desarrollar políticas, programas y acciones para fomentar en la sociedad valores culturales y cívicos que induzcan al respeto de la legalidad, establecimiento de los mecanismos de coordinación con el Ministerio Público, para apoyarlo en la investigación y persecución de los delitos y de los delincuentes y brindar auxilio a los grupos vulnerables y a las víctimas de hechos delictivos (Rico, 1997).

Para dar cumplimiento a estos objetivos, las fuerzas policiales, corporaciones o cuerpos de seguridad pública se constituyen en las instituciones adecuadas con miras a la prevención y disuasión de la criminalidad. Sociólogos, antropólogos y politólogos graduados deberían ser los integrantes de estos cuerpos especializados, los cuales no requieren de armas empleadas por las fuerzas militares.

Cabe destacar que en la mayoría de países existe una clara diferenciación entre la defensa nacional y la seguridad pública e interior (Murray, 1994). La primera tarea recae sobre las Fuerzas Militares, en tanto que la segunda, sobre las policías y fuerzas de seguridad. Estas dos últimas, por su propia naturaleza y carácter, dependen 
de los ministerios del interior, responsables de la buena convivencia nacional.

En Colombia, particularmente, la Policía Nacional depende del Ministerio de Defensa y de ahí su carácter militarizado como pocas en el mundo. Esta decisión política ha causado infinidad de inconvenientes por la confusión de roles, extralimitación de funciones y en no pocas oportunidades, la suplantación de la línea de mando en los cuerpos armados (Cadena, 1999).

La diferencia entre los roles de los cuerpos armados se observa con mayor claridad en los países desarrollados, donde se sostiene que la misión de un ejército es la defensa contra enemigos externos ${ }^{7}$, y se considera que el poder armado es simplemente una herramienta del gobierno, un instrumento de la política (Cope, 1997). Por tanto, normalmente el tipo de fuerzas militares que posee un país está íntimamente relacionado con el tipo y objetivos de su gobierno, es decir, con su proyecto de nación.

En ese proyecto de nación, se encuentran las estrategias definidas en razón de las amenazas, es decir, los planes de guerra que son y deben ser asunto de las fuerzas militares bajo la responsabilidad de la dirigencia política que detenta el poder civil. Me refiero a Estados consolidados con constituciones claras y permanentes y en los que las costumbres políticas no requieren interpretaciones coyunturales; en los que estos temas importantes son manejados por personas preparadas, con experiencia y compromiso por su patria.

La seguridad ambiental es la minimización proactiva de las amenazas antropogénicas a la integridad funcional de la biosfera y su componente interdependiente humano

7 Cabe citar la ya clásica obra de Stern, Frederick Martin, El Ejército Ciudadano. Biblioteca del Oficial, Volumen 509, Buenos Aires, Círculo Militar, mayo de 1961.
(Barnett, 1997). La protección del medio ambiente, los problemas demográficos, la pobreza y el cuidado del hábitat ya no son compatibles con una gestión particular de los bienes públicos (Bertrand, 2000) ${ }^{8}$. Un elemento interesante de esta definición es su enfoque hacia la acción. ¿Qué se puede hacer por la minimización proactiva?, lo que es de especial interés para la formación de profesionales. Otra reflexión que se deriva de esta definición, es que la seguridad ambiental no preocupa solamente a las agencias tradicionales de seguridad estatal ni a los ejércitos, sino que involucra a muchos actores de la sociedad civil, incluyendo a los mismos ciudadanos.

Así como se ha despertado el interés por el tema de la seguridad ambiental, hay corrientes de pensamiento que se alarman frente a esta tendencia. Uno de los argumentos parte de la interpretación de que el término seguridad ambiental fue acuñado con el solo propósito de ubicar el medio ambiente en el ámbito de la "alta política” (Lodgaard, 1992, citado en Gleditsch, 1998). Existe también el peligro de militarización del tema, es decir, la participación de los militares en la definición de agendas que no deberían ser de su incumbencia. De hecho, hay muchos aficionados a la geopolítica que aseguran que la próxima misión de los ejércitos tendrá que ver con la protección del medio ambiente.

La seguridad científica y tecnológica, entendida como la posibilidad del mayor aprovechamiento de resultados de la investigación científica y la invención tecnológica, aplicados siempre al mejoramiento de la calidad de vida en total armonía con el entorno y todas las especies vivientes. Este campo no puede concebirse sin un marco ético que sea el sustento del progreso en general (Foros México 1998-2007). Con razón se afirma que los países

8 De este y otros autores se puede encontrar importante bibliografía en el proyecto denominado "Biblioteca virtual. Modelo Económico mundial y la conservación del Medio Ambiente". 
que han logrado un alto grado de desarrollo, son aquellos que han invertido eficientemente en actividades de investigación científica. La industrialización, junto con el aprovechamiento de la tecnología, son elementos de vital importancia para el logro de la seguridad científica.

La seguridad jurídica es un principio del derecho, universalmente reconocido, que se entiende y se basa en la "certeza del derecho", tanto en el ámbito de su publicidad como de su aplicación, y representa la seguridad de que se conoce, o puede conocerse, lo previsto como prohibido, mandado y permitido por el poder público respecto de uno para con los demás y de los demás para con uno. La palabra seguridad proviene del latín securitas, la cual deriva del adjetivo securus que significa estar seguros de algo y libres de cuidados. El Estado, como máximo exponente del poder público y primer regulador de las relaciones en sociedad, no solo debe establecer las disposiciones legales a seguir, sino que en un sentido más amplio, tiene la obligación de crear un ámbito general de "seguridad jurídica" al ejercer el poder político, jurídico y legislativo.

La seguridad jurídica es, en el fondo, la garantía dada al individuo por el Estado de modo que su persona, sus bienes y derechos no serán violentados o que, si esto llegara a producirse, le serán asegurados por la sociedad, la protección y reparación de los mismos. En resumen, la seguridad jurídica es la "certeza del derecho" que tiene el individuo de modo que su situación jurídica no será modificada más que por procedimientos regulares y conductos legales establecidos, previamente publicados (Carbonel, 2000).

La seguridad social se refiere principalmente a un campo de bienestar social relacionado con la protección o la cobertura de las problemáticas socialmente reconocidas, como la salud, la pobreza, la vejez, las discapacidades, el desempleo en las familias con niños y otras afines. La Organización Internacional del Trabajo (OIT), en documento publicado en 1991, denominado Administración de la seguridad social, definió la misma como:

\begin{abstract}
...la protección que la sociedad proporciona a sus miembros, mediante una serie de medidas públicas, contra privaciones económicas y sociales que, de no ser así, ocasionarían la desaparición o una fuerte reducción de ingresos por causa de enfermedad, maternidad, accidente de trabajo, o enfermedad laboral, desempleo, invalidez, vejez y muerte; y también la protección en forma de asistencia médica y de ayuda a las familias con hijos.
\end{abstract}

La seguridad alimentaria nacional se refiere a la disponibilidad suficiente y estable de alimentos, el acceso y el consumo oportuno y permanente de los mismos en cantidad, calidad e inocuidad por parte de todas las personas, bajo condiciones que permitan su adecuada utilización biológica, para llevar una vida saludable y activa. Para dar cuenta de los avances en el ámbito de la seguridad alimentaria y nutricional, los países cuentan con una serie de instituciones y programas, que desde diferentes sectores respaldan este proceso (Planeación Nacional, 2004). Mientras este ensayo se escribe, en el Cuerno Africano, 10 millones de personas afrontan situaciones de hambre por problemas ambientales y sobre todo, por negligencia de los dirigentes políticos regionales.

\section{El derecho humano al agua}

Expertos asistentes al Foro Mundial del Agua se han reunido en varias oportunidades para debatir la escasez de agua, que es el mayor desafío que enfrenta la humanidad en la actualidad; no obstante, millones de personas todavía carecen del recurso, problema que podría agravarse debido al rápido crecimiento de la población y al cambio climático. La ONU ha advertido que a medida que el planeta se caliente y se seque, podríamos presenciar 
conflictos y guerras a causa de este recurso vital en el corto y mediano plazo.

El agua no debería ser vista como un negocio. El agua debe ser un derecho humano fundamental. Por eso, en diferentes lugares del planeta, las propuestas no se circunscriben exclusivamente a impedir su privatización, sino a propiciar su desprivatización, lo que derivaría en la prohibición para la venta de derechos o permisos de uso y concesiones que conducen al acaparamiento del agua por parte de unos pocos en desmedro de las mayorías. En algunos países, incluso, el derecho al agua ha sido considerado en las nuevas constituciones y por eso afirman sus ciudadanos que no se puede llegar a acuerdos que atropellen la Carta Magna. El derecho humano al agua es fundamental e irrenunciable, constituyéndose en lo que jurídicamente se denomina un bien público puro (Lorino, 1993) y por tanto, patrimonio nacional de uso general ${ }^{9}$.

Para conseguir este logro, ha sido y seguirá siendo necesaria una alta participación y movilización de grupos de presión, particularmente de los movimientos ecologistas, indígenas y campesinos, unidos férreamente por la defensa del agua. Esa presencia y ese aporte han sido meritorios, sin minimizar el trabajo de muchos intelectuales

9 El concepto de bien público puro tiene relación con aquellos que no son suministrados por el mercado o si lo son, la cantidad suministrada es insuficiente. Un ejemplo a gran escala es la defensa nacional, y otro a pequeña escala, las ayudas a la navegación, tipo boyas luminosas. Estos bienes públicos puros tienen dos propiedades básicas: en primer lugar, no cuesta nada que otra persona más disfrute de sus ventajas. Formalmente, el hecho de que un individuo adicional disfrute del bien tiene un coste marginal nulo. No cuesta más defender a un país de un millón y una persona que defender a uno de un millón. En segundo lugar, es difícil o imposible que no se disfrute del bien público. Si nuestra política de defensa nacional consigue evitar un ataque de otro país, todos nos beneficiamos; no es posible excluir a ninguna persona de estos beneficios. y científicos; cabe resaltar que la contribución de las organizaciones de la sociedad civil comprometidas desde hace muchos años con la defensa del agua, también ha sido importante en esta campaña a nivel mundial.

Para sorpresa de todos, un país del Tercer Mundo, Ecuador, ha incluido en su Constitución el derecho al agua de manera categórica. En concreto, en el artículo 12, se determinó que "el derecho humano al agua es fundamental e irrenunciable. El agua constituye patrimonio nacional estratégico de uso público, inalienable, imprescriptible, inembargable y esencial para la vida". En consonancia con esta definición constitucional, desde el inicio, en el artículo 3 de la Constitución se estableció como el primer deber primordial del Estado "garantizar sin discriminación alguna el efectivo goce de los derechos establecidos en la Constitución y en los instrumentos internacionales, en particular la educación, la salud, la alimentación, la seguridad social y el agua para sus habitantes".

A partir de esa definición inicial, en el pleno de la Asamblea Constituyente en Montecristi se aprobaron tres puntos fundamentales: 1. El agua es un derecho humano; 2. El agua es un bien nacional estratégico de uso público, y patrimonio de la sociedad; 3 . El agua es un componente fundamental de la naturaleza, la misma que tiene derechos propios a existir y mantener sus ciclos vitales. Como puede verse claramente, con estas medidas se hace énfasis en los conceptos soberanía y autodeterminación, conceptos que en lo político giran en torno a la idea del Estado nacional y la independencia, aún sabiendo que independencia significa control real, aspectos estos que en la mayoría de los Estados desaparecieron hace 
varios años frente al poderío económico de empresas de alcance transnacional (Terry y Philipe, 1991, p. 10) ${ }^{10}$.

En Ecuador, la trascendencia de las disposiciones constitucionales es múltiple. En tanto derecho humano, se superó la visión mercantil del agua y se recuperó la del "usuario", es decir, la del ciudadano y de la ciudadana, en lugar del "cliente", que se refiere solo a quien puede pagar. En tanto bien nacional estratégico, se rescató el papel del Estado en el otorgamiento de los servicios de agua, reconociendo que se puede ser eficiente. En tanto patrimonio, se pensó en el largo plazo, liberando al agua de las presiones cortoplacistas del mercado y la especulación. Y en tanto componente de la naturaleza, se reconoció en la nueva Constitución ecuatoriana la importancia del agua como esencial para la vida de todas las especies, y se enfatizó en el respeto a la naturaleza.

\section{Importancia del agua en la vida humana}

El agua nos rodea e integra como seres vivos. Proporciona múltiples usos esenciales para la supervivencia como la hidratación o alimentación. Facilita la producción agrícola, la higiene corporal y de los alimentos, así como otros beneficios de recreación o ligados a la religión presentes en todas las culturas. Puede sorprender, entonces, que su disfrute no haya sido todavía garantizado explícitamente como derecho humano fundamental en ningún

$10 \mathrm{Al}$ determinar que el agua es un derecho humano, fundamental e irrenunciable, es claro que en este caso el Estado asume sus obligaciones con seriedad, pues dentro de las funciones del Estado podemos distinguir tres esenciales, a saber: 1) El pacto social que resulta de los acuerdos institucionales que traducen la naturaleza organizacional y la organización racional del sistema social y político; 2) Proporcionar la seguridad ciudadana, y 3) Respetar la identidad y la cultura dependiendo del ámbito en el cual se desenvuelve una comunidad. texto jurídico internacional, con las garantías frente a los poderes públicos y las personas que se derivan de esta categorización. Dar las garantías necesarias para que la gente cuente con la cantidad y calidad de agua requerida para hoy y mañana, es el gran reto que tenemos en nuestras manos.

Las manifestaciones ancestrales de la importancia del agua en la vida humana evidencian la conciencia universal del valor supremo que tiene el recurso como factor para el logro de las cotas básicas de desarrollo material y espiritual del ser humano. Como contrapunto con esta esfera axiológica, el Informe sobre Desarrollo Humano del 2006, titulado Más allá de la escasez: Poder, pobreza y la crisis mundial del agua, elaborado por el Programa de las Naciones Unidas para el Desarrollo (PNUD), muestra un panorama sombrío en la satisfacción de esta necesidad primaria. Gracias a la labor de esta organización hoy sabemos que varios millones de personas en el mundo no tienen acceso a agua potable y otras no gozan de servicios sanitarios mínimos. El acceso deficiente al agua potable se ha convertido en la segunda causa de muerte infantil en el planeta.

Además de afectar la vida y la salud, las dificultades de acceso adecuado al agua potable o de saneamiento repercuten negativamente sobre la eficacia de otros derechos esenciales para la dignidad humana. La disponibilidad de agua adecuada condiciona el derecho a la alimentación o al desarrollo, por su valor fundamental en los procesos productivos. Dado que en algunas comunidades es la mujer quien asume la función principal de buscar y acarrear agua en múltiples ámbitos socio-culturales de orden rural, las limitaciones de acceso físico al agua contribuyen también a perpetuar la discriminación de género. El derecho a la educación infantil se frustra de forma inexorable como consecuencia del consumo de aguas contaminadas al tratarse de seres más expuestos 
a padecer enfermedades incapacitantes para llevar una vida normal.

Si se compara con la protección jurídica expresa de la que gozan otras necesidades esenciales de los seres humanos, como la alimentación, la salud o la vivienda, el derecho humano al agua, en toda su extensión figurable, apenas ha tenido aparición explícita en contadas normas de carácter interno o internacional. Como es sabido, la Declaración del Milenio de la ONU fijó entre los objetivos del desarrollo reducir a la mitad, para el año 2015, el porcentaje de personas que no tienen acceso al agua potable o no pueden costeárselo.

Así se firmó la Declaración de Johannesburgo, adoptada en la Cumbre Mundial sobre Desarrollo Sostenible de 2002. Como explica el Informe de Desarrollo Humano del 2006, el problema social no ha variado de modo significativo desde estas declaraciones solemnes. La realidad actual muestra que si no se adoptan a tiempo las medidas adecuadas, los efectos del cambio climático en curso podrían recrudecer el problema y convertir el agua en un foco más de conflictos violentos internos e internacionales. Es necesaria entonces la adopción y adecuación de políticas públicas que comprometan a las naciones en la solución de este grave problema (Meny y Thoenig, 1992 $)^{11}$.

11 En el siglo XX, básicamente fueron tres los modelos teóricos que contribuyeron al conocimiento y mejoramiento de las políticas públicas: el primero, centrado en un enfoque social que privilegiaba al individuo y al pluralismo social, concibió el Estado desde una perspectiva funcionalista para atender solamente las demandas sociales. El segundo insistía en atribuir al Estado la condición de instrumento al servicio de una clase o de grupos específicos. El tercero intentaba encontrar un camino intermedio, dedicándose a interpretar los equilibrios y desequilibrios que se establecían entre el Estado y la sociedad y que las políticas públicas permitían traducir. Estos tres modelos no desatendían las implicaciones para la acción pero implícitamente confirmaban que los análisis de política se fundamentan en la filosofía política.

\section{Estatus jurídico del derecho fundamental al agua}

Este ensayo intenta llamar la atención de las autoridades sobre la problemática y las responsabilidades que les atañen en el componente de calidad del derecho humano al agua. Los ciudadanos debemos rechazar todas las formas de privatización que muestran falsos beneficios para incursionar en el negocio del agua sin importar los efectos sociales y económicos para las regiones.

Teóricamente, el agua alcanza para 20 mil millones de personas, lo que equivale a tres veces la población mundial. Sin embargo, el modelo económico neoliberal y el tipo de gestión que se le da no hace del agua un recurso renovable ni permite que esté disponible para todos, contraviniendo los preceptos de la economía social que pregonan la equitativa distribución de los recursos, después de una racional explotación.

El hecho real es que tanto a nivel nacional como internacional, la privatización ha conducido a un encarecimiento del servicio público de acueducto. Este fenómeno ha generado resistencia a nivel global, comenzando por Francia. En América Latina son suficientemente conocidos los casos de Bolivia y Uruguay, donde un reciente plebiscito estableció el carácter público del agua y prohibió la prestación del servicio de acueducto por parte de empresas privadas. En Colombia, en repetidas ocasiones, en algunas ciudades se han quemado las facturas de servicio de acueducto en protesta al mal servicio y a los altos costos del mismo.

La privatización ha traído como consecuencia un encarecimiento del servicio de acueducto para los usuarios ahora convertidos en "clientes". En Colombia, la privatización de algunos procesos de la operación de la empresa 
de Acueducto de Bogotá ha generado aumentos de tarifas del 126\% para el estrato uno, de 58\% en el estrato dos y de $55 \%$ en el estrato tres, lo que muy seguramente ocurrirá con otras empresas de entregarse al sector privado el área comercial. Así las cosas, familias enteras de los estratos uno y dos, no pueden acceder al agua por incapacidad económica de pagar los costos del metro cúbico ${ }^{12}$.

Mares y océanos son una abundante fuente de recursos hídricos del planeta. La tecnología ha conseguido producir agua de calidad a un coste razonable. Se estima que nuestro planeta dispone de una masa de agua de 1.386 millones de kilómetros cúbicos en sus tres estados: hielo, líquido y vapor. De todo este volumen, la fracción de agua dulce representa solo el 2,5\%. De ese porcentaje, el ser humano dispone de manera directa de la fracción de acuíferos profundos (29,9\% del agua dulce disponible), que es profusamente empleada en muchos lugares del mundo. Además, disponemos del agua de ríos, lagos y acuíferos superficiales. Esta es la fracción más interesante que se renueva a través del ciclo hidrológico y de la diferencia entre el agua precipitada y evaporada anualmente en las masas continentales, que alcanza 44.800 kilómetros cúbicos.

Conocidas estas reservas se intuye que los recursos disponibles de manera rápida y directa son ciertamente limitados. El problema se agudiza si se estudian las diferencias en la disponibilidad de recursos por zonas geográficas y por habitante. Mientras que hay zonas con grandes

12 Los estratos en Colombia son medidas por medio de las cuales se buscó clasificar las viviendas de los habitantes según la calidad del entorno y los materiales utilizados para la construcción de las mismas. Esta clasificación tuvo como finalidad identificar las viviendas más pobres para otorgarles subsidios. Los estratos se clasifican del uno al seis y aunque su aplicación se hace invocando el principio de solidaridad, en realidad constituyen un abuso porque el Estado descarga su responsabilidad sobre los trabajadores de mayores ingresos. excedentes, hay otras áreas de recursos muy escasos o muy pobladas, esto es, que ejercen una gran demanda de agua. Es en estas zonas donde la situación puede llegar a ser, en ocasiones, crítica.

La grave crisis por el agotamiento del agua, acentuada por el cambio climático, es la alarmante conclusión de diferentes informes de comisiones de expertos de distintas organizaciones internacionales que auguran malos tiempos para el futuro de la humanidad. Si no se toman medidas urgentes para conservar el agua dulce, se aproxima una crisis severa, lo cual se puede concluir del informe elaborado por el grupo de científicos de la comisión de la ONU. Según este informe se prevé que entre 75 y 250 millones de africanos sufran escasez de agua potable que repercutirá en perjuicio de la producción agrícola de sus países y el descenso de la pesca en zonas como la de los Grandes Lagos.

Pero este no será el último informe donde se advierta a los países africanos de la crisis del agua que ya han empezado a padecer. En el último informe del Programa de Naciones Unidas para el Desarrollo (PNUD), presentado en Sudáfrica en noviembre del 2009, se señaló a las políticas cerradas de gestión de agua de los gobiernos africanos como factores agravantes de escasez en este continente junto a la pobreza, la desigualdad y las relaciones de poder. La explotación en exceso del agua en ríos que se están secando, ecosistemas degradándose, la ausencia de infraestructuras necesarias de canalización y tratamiento, escasa inversión en mejoras hídricas y alto precio del agua, son algunas consecuencias derivadas de estas nefastas políticas del agua.

Sin duda, la responsabilidad de estos males recae sobre las clases dirigentes, pues no es un secreto que el político se interesa más en la distribución de los productos, enfatizando su acción en las comunidades organizadas y no 
específicamente en los ciudadanos individualmente, y es que con esta actividad responden a su compromiso con los electores y no a la intención del beneficio público (Aguilar, 1992).

\section{El caso de Colombia}

En Colombia, en el siglo XX, antes de la década del noventa la situación del agua fue concebida como servicio público con responsabilidad social del Estado, al punto que el artículo 365 de la Constitución Política de 1991, estableció que los servicios públicos eran inherentes a la finalidad social del Estado, concibiéndose como deber de este, asegurar su prestación eficiente a todos los habitantes del territorio nacional.

Sin embargo, el gobierno a través de la Ley 142 del 11 de julio de 1994, se liberó de la responsabilidad de apoyar esta función social, dando origen a la libertad de competencia en el sector de agua potable, dificultando las condiciones de existencia de las empresas estatales, que debieron enfrentarse no solo con la problemática socioeconómica de la comunidad cada día más pobre, sino también con las transnacionales que amenazan con incursionar en el negocio del agua, peligro latente que conlleva la privatización de este servicio esencial para la vida.

El 25 de mayo de 2004, a través de la Resolución 287, el gobierno colombiano aplicó reformas a la metodología tarifaria que las empresas del sector de agua potable debían implementar, prohibiendo trasladar a la tarifa el pasivo pensional, de manera que las empresas que hoy no tienen recursos suficientes para responder por su pasivo de pensiones, se encuentran a punto de desaparecer. Esta nueva política del gobierno ordenó cobrar tarifa plena a todos los usuarios en caso de que las entidades territoriales no cumplieran con los subsidios que estén a su alcance, medida que se convirtió en grave amenaza para las empresas del Estado que han tenido como un criterio de fondo el balance social, por el impacto a los usuarios más pobres ${ }^{13}$.

La calidad del agua en Colombia, hay que decirlo, no es apta para el consumo humano en 801 municipios, como una clara demostración de la carencia de pertinencia social de diferentes gobiernos que han dedicado todos los recursos para la guerra. De 955 municipios analizados, el $84 \%$ no tienen agua apta para el consumo humano, según informe elaborado por la Defensoría del Pueblo con base en los resultados de las muestras de laboratorio de las secretarías de salud departamentales en el marco del derecho humano al agua. Solo en 82 municipios se está suministrando agua segura y 72 se encuentran cercanos a cumplir con los parámetros físico-químicos y microbiológicos establecidos en el Decreto 475 de 1998. Esto quiere decir que 13 millones 400 mil personas no están consumiendo agua de acuerdo a la norma, con los consecuentes riesgos para su salud ${ }^{14}$.

Colombia es uno de los países con mayor riqueza hídrica. De acuerdo con cifras del Ministerio de Ambiente y del Instituto de Estudios Ambientales, la oferta de agua superficial es casi 100 veces mayor que la demanda. Se estima que el beneficio que representa el recurso hídrico para el desarrollo del país equivale casi al 10\% de PIB.

13 Los grandes prestadores de servicio son las empresas que tienen más de 2.500 usuarios. En América Latina son grandes transnacionales las que se han hecho cargo de asumir la prestación de servicios públicos, homologando los costos por lo alto sin tener en cuenta el poder adquisitivo de los ciudadanos, afectando sobre todo a las clases menos favorecidas.

14 Cuando los seres vivos usamos el agua, la devolvemos al medio con menos calidad, pero la naturaleza dispone de mecanismos que le restituyen su pureza, para que pueda ser utilizada de nuevo. Los seres humanos vertimos a los medios acuáticos grandísimas cantidades de residuos, que hacen imposibles los procesos de reciclaje y depuración naturales de las aguas. Por eso muchos medios acuáticos están contaminados. 
Igualmente se ha estimado que los costos económicos de la contaminación equivalen al 3.5\% de PIB. El mayor problema consiste en que esa oferta es heterogénea, pues la mayor parte del recurso se encuentra en donde casi no hay gente; es decir, en la Orinoquía, Chocó y Amazonía. Eso riñe con la oferta en la zona Andina, en la que está el grueso de población y que tan solo cuenta con un 15\% de la oferta total. Registros de la autoridad ambiental en el Caribe demuestran que debido a las malas prácticas y a la deforestación, la oferta hídrica de la Sierra Nevada de Santa Marta ha disminuido notablemente ${ }^{15}$.

Colombia es el país con mayor extensión de páramos: 1.613.927 hectáreas, de las cuales se han afectado entre el 60 y $70 \%$ por la acción antrópica y se ha perdido gran potencial de su capacidad reguladora de agua. Pero ahora la mayor amenaza es el calentamiento global que solo puede ser mitigado mediante políticas estrictas convenidas por los países industrializados que hagan realidad sus propuestas de reducción de emisión de gases de efecto invernadero. De eso depende la supervivencia de nuestros páramos, la cual se encuentra en entredicho según las apreciaciones de los investigadores, quienes coinciden en señalar que en los próximos 100 años se podrían extinguir entre el 90 y el 100\% de los páramos del país $\left(\right.$ Castaño, 2004) ${ }^{16}$. Estos páramos son conocidos coloquialmente como verdaderas fábricas de agua.

15 La evapotranspiración comprende los procesos de evaporación y transpiración de las plantas, mediante los cuales, el agua que se encuentra en la tierra y parte de la que se encuentra en las plantas, regresa a la atmósfera en forma de vapor reiniciando el ciclo hidrológico.

16 El fin de los páramos se acerca, no sabemos cuándo, si no se toman las medidas a nivel mundial. La muerte de estos ecosistemas es una muestra más de la violencia con que el ser humano en su desarrollo desequilibrado pone una vez más estos ecosistemas en el filo de la navaja de la extinción.
El escenario futuro de Colombia no es nada optimista si se tienen en cuenta los pronósticos de un reciente informe de la Contraloría Delegada para el Medio Ambiente, en el que se advierte que pese al alto volumen de lluvias y la abundancia de fuentes hídricas, el país podría enfrentar graves problemas para garantizar la sostenibilidad del agua, al punto que en el 2015, el 66\% de los colombianos estará en riesgo de desabastecimiento en épocas secas.

\section{Complejidad de los ecosistemas frente a las políticas públicas en Colombia}

En 1995, en el mundo se extrajeron 3.906 kilómetros cúbicos de agua. Se ha proyectado que para el año 2025 la extracción de agua para uso doméstico, industrial y ganadero habrá incrementado, limitando la extracción de agua para riego, que aumentará solamente un cuatro por ciento, lo que restringirá a su vez la producción de alimentos. En la actualidad (2011), en todo el mundo se riegan unos 250 millones de hectáreas. El riego ha ayudado a aumentar los rendimientos y la producción de la agricultura y a estabilizar la producción y el precio de los alimentos.

Si bien los logros en materia de riego han sido extraordinarios, en muchas regiones su mal manejo ha reducido significativamente las fuentes del agua subterránea, dañado los suelos y reducido la calidad del agua. En cuanto a la seguridad alimentaria, la escasez de agua puede llevar a una caída de la demanda y aumento de los precios. Es posible que los precios de los principales cereales aumenten al doble y la demanda de alimentos podría verse considerablemente reducida, especialmente en los países 
en desarrollo. Los aumentos pueden tener un impacto todavía mayor en los consumidores de bajos ingresos ${ }^{17}$.

La hidrografía colombiana es extensa y muy rica. Los ríos más largos corren por las llanuras orientales hasta desembocar en el Orinoco y en el Amazonas. Esta distribución permite distinguir en Colombia cuatro vertientes y seis grandes cuencas: la vertiente Pacífico, la vertiente Caribe que incluye las cuencas Magdalena, Cauca, Atrato y el Catatumbo principalmente, la vertiente del Orinoco y la vertiente de la Amazonía. La vertiente del Pacífico la forman más de 200 ríos y se caracteriza por ser una de las más lluviosas del mundo; sus ríos son cortos y caudalosos por la cercanía de las montañas a la costa. La vertiente del Caribe es la más importante de Colombia porque en esta región vive la mayor cantidad de población del país y ha tenido los procesos de transformación más drásticos; es alimentada desde el llamado macizo colombiano o estrella fluvial colombiana. Comprende los ríos que corren de sur a norte, entre los grandes valles interandinos: el sistema Magdalena - Cauca y los ríos Atrato, Sinú y Catatumbo.

17 Los departamentos con suministro de agua segura para consumo humano en la mayoría de sus municipios son en su orden Quindío, Valle del Cauca y Caldas; por el contrario, los departamentos en que no se suministra agua apta para consumo humano en ninguno de los municipios son Amazonas, Cesar, Chocó, Bolívar, Caquetá, Guainía, Guajira, Guaviare, Nariño, Putumayo, San Andrés, Vaupés, Vichada y Santander. En Boyacá, de 104 municipios no cumplen 98; en Cundinamarca, de 104 no cumplen 92 y en Antioquia, de 117, no cumplen 89. Hay otros departamentos donde el porcentaje de municipios que no cumple también es muy alto: Meta con el 96.6\%, Magdalena con el 96.2\%, Cauca con el $91.4 \%$, Norte de Santander con el 88.4\%, Casanare con el $84.2 \%$, Sucre con el 84.6\%, Córdoba con el 78.6\% y Risaralda con el 75\%. En riesgo alto están 216 municipios del país. En Antioquia 5, en Arauca 1, Atlántico 2, Boyacá 35, Caldas 2, Caquetá 10, Casanare 6, Cundinamarca 11, Guainía 1, Guajira 5, Guaviare 4, Huila 2, Chocó 1, Magdalena 13, Meta 16, Nariño 50, Norte de Santander 8, Putumayo 6, Quindío 1, Santander 32, Sucre 8 y Vaupés 2.
La cuenca del Orinoco comprende algo más de 320.000 kilómetros cuadrados del territorio colombiano. Sus principales afluentes en Colombia son los ríos Meta, Arauca, Vichada y Guaviare. La vertiente del Amazonas comprende los ríos más largos del país que recorren las regiones llanas y selváticas de la Amazonía. A Colombia le corresponden 116 kilómetros del Amazonas, al sur del trapecio amazónico. Los ríos colombianos que forman parte de la cuenca del Amazonas son muchos, pero se destacan el Negro o Guainía, el Caquetá, el Vaupés y el Putumayo.

La zona comprendida entre los ríos San Jorge y Cauca constituye la mayor depresión cenagosa del país conocida como "depresión momposina". Tiene un área de 6.000 kilómetros cuadrados y se extiende desde Zambrano y Plato por el norte, hasta Ayapel en el sur y desde Caimito y San Marcos en el oeste, hasta El Banco en el oriente. Constituye un inmenso sumidero sometido a un constante proceso de hundimiento ocasionado por el peso de los sedimentos traídos por las aguas de inundación ${ }^{18}$. Este fenómeno de hundimiento o subsidencia fluctúa entre 0.9 y 2.5 milímetros anuales.

La Ciénaga Grande de Santa Marta es una laguna costera ubicada en la margen derecha del río Magdalena en su desembocadura. Cubre un área aproximada de 4.280 kilómetros cuadrados, de los cuales 730 son espejos de agua correspondientes a más de 20 lagunas interconectadas entre sí a través de caños. Los humedales de la Orinoquía están presentes en las sabanas inundables del departamento de Arauca, zonas inundables del río Meta

18 La sedimentación tiene relación con la materia sólida que después de haberse mantenido flotando, se moviliza al fondo del cuerpo de agua por motivo de la gravedad. En la mayoría de los casos, la sedimentación está relacionada con el mal uso del suelo y movimientos de tierra por acciones naturales o antrópicas, en todo caso dañinas para el medio ambiente. 
y Casanare y en los complejos de humedales que forman el río Vichada y el Tomo en el tercio final antes de desembocar al río Orinoco. Las áreas inundables formadas por las cuencas hidrográficas antes mencionadas representan el 32\% de la superficie inundable del país. Algunos estudios clasifican estas áreas inundadas y otros cuerpos de agua en lagos, lagunas, caños, esteros, morichales, ciénagas y pantanos.

Los estudios actuales de exploración y evaluación de aguas subterráneas a nivel regional y local realizados en Colombia permiten identificar algunas áreas donde existe un potencial en la oferta en cantidad y calidad para diferentes usos. Estudios hidrogeológicos realizados en el país por diferentes entidades encargadas de investigación y planificación del uso, manejo y aprovechamiento de aguas subterráneas, estiman preliminarmente que el área total de Colombia con posibilidades de contener importantes almacenamientos de aguas subterráneas, alcanza los 415.000 kilómetros cuadrados (36\% del país), de los que se han estudiado un $15 \%$ aproximadamente.

De cinco grandes cuencas, solo la del Caribe occidental está completamente transformada, mientras la Amazonía está conservada. Las cuencas que se extienden desde las montañas hasta las tierras bajas, tienen zonas conservadas en partes altas, en pendientes abruptas y en zonas pantanosas. De las cuencas medias, muchas están completamente transformadas, al lado de algunas preservadas en la misma cuenca principal. Así, 50 de las cuencas medias están transformadas, en especial la cuenca del río Magdalena, que es la cuenca social y económicamente más significativa. Mientras que 27 de las cuencas medias no están perturbadas y drenan el $53 \%$ del país, pero no incluyen ninguna cuenca de los Andes o del Caribe, otras 33 cuencas, esparcidas por el territorio, están parcialmente transformadas.
Las principales causas de la pérdida de coberturas boscosas en el país son: la ampliación de la frontera agrícola, en particular el establecimiento de pastos para ganadería; el establecimiento de cultivos ilícitos que está afectando principalmente la Amazonía colombiana con cerca de 100.000 hectáreas entre coca y amapola. Por último, una causa asociada a la pérdida de bosques son los incendios forestales que representaron cerca de 400.000 hectáreas entre 1985 y 1995.

De acuerdo con muestreos y mediciones del Instituto de Estudios Ambientales y Meteorológicos, durante el 2003 los ríos que presentan deterioro alarmante en su calidad son el Bogotá, Medellín, Chicamocha, alto Cauca, Lebrija y Chulo, por los vertimientos que reciben de origen doméstico e industrial de las áreas más pobladas del país, y presentan resultados críticos en todas las variables. El número de substancias que han sido sintetizadas es del orden de algunos miles, y en Colombia se utilizan actualmente más de 300 ingredientes activos en casi un millar de formulaciones.

Los efectos del cambio climático, demostrado en el aumento de la temperatura mundial en cerca de un grado centígrado en el último siglo, tienen diversas formas. En el país pueden distinguirse en la oferta hídrica para los diversos usos, en la producción agropecuaria, especialmente de los cultivos transitorios y en la salud de las personas. El abastecimiento de los acueductos y las actividades agropecuarias se reducen, dificultando los procesos de planificación y la vida diaria de los colombianos. Los rendimientos de los cultivos dependen de los factores ambientales y tecnológicos, especialmente la precipitación y la humedad, reduciendo los niveles de producción y por supuesto de ingreso en los agricultores.

El aumento de la temperatura y la variación de factores como la humedad generan incrementos en las 


\section{Čír'́rế 19}

enfermedades tropicales como las infecciones respiratorias agudas, tuberculosis, malaria, fiebre amarilla, dengue, cólera, que han coincidido con anomalías climáticas por el efecto de la sinergia de este con otros elementos del medio. La conservación del agua en el país está asociada directamente con el cambio en el modelo de ocupación del territorio, esta es su causa principal, que de manera sinérgica con otros factores como los cambios en el clima, genera la crisis actual en relación con el deterioro del agua en el país ${ }^{19}$.

El sector que usa la mayor cantidad de agua tiene relación con el abastecimiento de agua para riego. Si se presume que parte de la agricultura se trabaja en concordancia con los ciclos hidrológicos se entenderá que su demanda de agua se suple con el balance hídrico, entonces los requerimientos críticos de agua se circunscriben a los distritos de riego que corresponden a 3'499.000 de hectáreas con una demanda cercana a los 1.757'771.000 metros cúbicos que representan el 32,2\% del total del consumo de agua en el país.

El sector industrial manufacturero se encuentra localizado en las grandes ciudades y en sus alrededores conformando centros industriales. La industria urbana y la gran industria consumen el 6,6\% del total del agua en Colombia y aunque mucha de ella tiene sus propias fuentes de abastecimiento como pozos profundos, también demanda una gran cantidad de agua tratada en los acueductos domésticos. La demanda hidroeléctrica y termoeléctrica se estima en 48.000 millones de metros cúbicos, diez veces superior al resto de los usuarios.

19 El ciclo hidrológico es el proceso del movimiento continuo del agua en el planeta. Las moléculas de agua pueden pasar por diferentes estados, ya sea hielo, vapor o líquido, antes de retornar a su estado inicial.
En un año seco promedio, el índice de escasez afecta a 209 cabeceras municipales en las categorías de alto y medio, involucrando al menos 18 millones de personas. Los mayores valores se presentan en el valle alto y medio del río Cauca, en el altiplano cundiboyacense, en el cañón del Chicamocha y el Suárez, en el cañón del Zulia, en la Guajira, en San Andrés y Providencia y en algunos municipios dispersos de la costa Caribe. En el resto del país el índice es mínimo o poco significativo. En relación con la vulnerabilidad que mide cualitativamente el grado de fragilidad del sistema hídrico para mantener una disponibilidad segura ante la sequía, se sabe que 14 municipios presentan un nivel muy alto en Valle, Cundinamarca, Boyacá, Santander, Norte de Santander y la Guajira. Las categorías media y alta vulnerabilidad se presentan en la zona Andina y en toda la región Caribe. Pero la vulnerabilidad media también se extiende hacia la Orinoquía, especialmente Casanare.

Pese al incremento en inversión pública, los colombianos seguimos consumiendo agua de mala calidad. De acuerdo con la información del Departamento Nacional de Planeación (DNP) respecto al índice de calidad de vida, este se incrementó entre $60.2 \%$ en 1985 a $75.7 \%$ en el 2000. El incremento del índice se debió principalmente al aumento de indicadores como abastecimiento de agua (4.8 a 6.3), recolección de basuras (0 a 5.1) y personas por cuarto (5.8 a 10.9). Esto quiere decir que la calidad de vida ha mejorado por una mayor cobertura de los servicios públicos básicos de agua y saneamiento básico. La calidad de vida rural sigue siendo mucho más baja en estas zonas que en las cabeceras municipales y se presentan marcadas diferencias con relación a las coberturas de los servicios básicos.

De acuerdo con el informe del control de la calidad del agua en Colombia 2006, de la Superintendencia de Servicios Públicos, de un total de 231 municipios 
evaluados, al 18\% se le suministró agua apta para el consumo humano; es decir, 189 municipios recibieron agua no potable, lo que representa un $82 \%$. De un total de 23‘908.989 colombianos que recibieron agua, a 8'187.542 se les suministró agua no potable, lo que representa un 34\% del total de la población. El estudio de la Defensoría del Pueblo en 2005, corroboró los datos de la Superintendencia de 2003. De las pruebas analizadas, se concluyó que el agua que se consume en el país no cumple en su mayoría con el parámetro del 95\% en los aspectos biológico y fisicoquímico. Especialmente, se afecta la población más vulnerable, como son los menores de edad y todas aquellas personas que viven en condiciones de extrema pobreza.

La cobertura del alcantarillado nacional total para viviendas en 1985 solo alcanzaba el 59.5\%, aumentó al 63\% en 1993 y para el 2000 llegó al 73.3\%; por el contrario, en las zonas rurales era del $11.3 \%$ en 1985 y se incrementó la cobertura al $14.4 \%$ en 1993 y al 37\% en el 2000, corroborando la tendencia a la inversión en los cascos urbanos de los municipios. Los departamentos con coberturas menores al 30\% son, de menor a mayor: Vichada, Guaviare, Vaupés, Chocó, Córdoba, San Andrés, Boyacá, Guainía, Casanare y Putumayo. Entre el 30 y el 50\% de cobertura en alcantarillado se encuentran departamentos como Sucre, Arauca, Bolívar, Guajira, Nariño, Magdalena, Cauca, Caquetá, Amazonas, Cesar y Cundinamarca. Finalmente, los departamentos que tienen coberturas superiores al 50\% de las viviendas son: Tolima, Meta, Huila, Norte Santander, Santander, Atlántico, Antioquia y Caldas. Con coberturas mayores al 80\% están Valle, Risaralda, Quindío y Bogotá.

Según cálculos oficiales, dotar con sistemas de tratamiento de aguas residuales solo a 300 municipios que cumplen las condiciones técnicas previstas, tendría un costo cercano a los 3.400 millones de dólares, incluyendo 800 millones requeridos para completar las redes primarias. Los recursos disponibles en las diferentes fuentes podrían financiar aproximadamente el $12 \%$ de los requerimientos de inversión. Pretender financiar el faltante con aumentos tarifarios, aunque legalmente posible, implicaría incrementos adicionales a los planeados por desmonte de subsidios de hasta el $50 \%$ en el estrato uno, lo que sería difícil dada la situación política y social del país.

En Colombia, el servicio de agua y alcantarillado es de competencia municipal. Actualmente, existen más de 2.000 prestadores, de los cuales 830 se encuentran debidamente registrados. De esta muestra, solo el 12\% asumió forma de empresa de servicios públicos; de estas sociedades, el $61 \%$ son privadas, $28 \%$ mixtas y el resto oficiales $^{20}$. La gran mayoría de prestadores se han acogido a otras figuras de excepción permitidas por la ley de servicios públicos como prestación directa por el municipio y comunidades organizadas. El 32\% de las entidades son prestadores en áreas rurales.

La inversión gubernamental en agua potable se incrementó a finales de la década de 1980. Por la Constitución

20 Los procesos de privatización que las entidades oficiales del sector destacan son: el caso de la Triple A en Barranquilla, adquirida por operadores españoles; en Cartagena se llevó a cabo el proceso de participación privada con Aguas de Barcelona; en Montería se adjudicó un contrato de concesión a la empresa Proactiva; en Tunja, Santa Marta y Maicao se realizaron procesos de vinculación de particulares a la prestación de los servicios. En Bogotá, ciudad con el 14\% de los habitantes del país, los servicios de acueducto y alcantarillado son prestados por la Empresa de Acueducto y Alcantarillado de Bogotá (EAAB), sociedad por acciones de carácter oficial. En Medellín, los servicios de saneamiento están a cargo de las Empresas Públicas de Medellín (EEPPM) y en Cali son atendidos por EMCALI, empresas de sus respectivos municipios. El sector de agua potable está atomizado. Sin embargo, en municipios pequeños, en general, la administración sigue a cargo del servicio, aún cuando se haya dado una separación de cuentas y se haya mejorado la información sobre la prestación de los servicios. 
Nacional que incorporó las nuevas instituciones y la descentralización, el gasto en este rubro se disparó teniendo su máxima expresión en 1993, para luego estabilizarse entre el 1.5 y el $2.5 \%$ del gasto social nacional. Las causas evidentes en el atraso de los sistemas de servicios públicos en los municipios colombianos son la baja asignación presupuestal desde el nivel central, una escasa o nula planificación del sector, por supuesto la corrupción administrativa, que aún se mantiene, y un proceso acelerado de concentración poblacional en los cascos urbanos. Por diversos motivos, estas causas dispararon la demanda doméstica de agua potable y saneamiento básico. Se cambió la forma y la magnitud de las transferencias y los procesos de la administración local. Esta tendencia fue muy importante hasta el 2000 y ha comenzado a revertirse con los procesos de centralización y reformas a la legislación reciente como la Ley 715.

Como puede verse, la inversión pública ha aumentado. Hay una regulación estricta y libertad de mercados pero seguimos consumiendo agua no potable en la mayoría del país. La política pública al respecto ha incrementado las tarifas (Reglamentación CRA). Este aumento tarifario ha reducido los niveles de consumo por usuario cercanos a 25 metros cúbicos por mes hasta promedios por debajo de 20 metros cúbicos.

A partir de las leyes expedidas bajo el nuevo marco constitucional, los recursos del presupuesto nacional se destinan a subsidios. En acueductos, los balances entre contribuciones y subsidios se realizan a nivel municipal, y es muy común encontrar déficit en aquellas localidades con participaciones muy bajas de usuarios contribuyentes. En este caso, el Estado no asume ningún compromiso por cerrar estos desbalances. Se estima que en los próximos años se destinarán 250 millones de dólares anualmente, que permitirán cubrir una cifra cercana a 10.000 pesos por usuario subsidiable al mes, que representa cerca de una tercera parte del costo total del servicio.

El balance entre subsidios y aportes solidarios presenta un déficit de alto riesgo. Como resultado del seguimiento a los recursos otorgados para el cubrimiento de subsidios en los servicios de acueducto y alcantarillado, en 2002 el déficit en una muestra de 120 empresas era de 270 mil millones de pesos. El resultado altamente negativo, entre subsidios y aportes pone en riesgo el suministro del servicio de acueducto y alcantarillado a los estratos más bajos.

La participación privada no es muy probable como solución para los municipios menores o en áreas rurales con usuarios muy dispersos. Los altos costos de transporte limitan las posibilidades de desarrollar sistemas regionales para la producción y distribución de agua. El mercado municipal es, por naturaleza, en el caso de este servicio, la escala óptima desde el punto de vista de los activos y desde el punto de vista de los usuarios que no quieren pagar más para que unos pocos se llenen los bolsillos.

\section{Conclusiones}

Hablar de seguridad humana en el siglo XXI, constituye el reconocimiento de la importancia del animal político al que se refería Aristóteles cuando señalaba a la politica como "el arte de gobernar y de redistribuir los recursos". Efectivamente, la humanidad ha entendido que no puede haber nada por encima de sus semejantes y en tal virtud, en un acto reflexivo de emergencia, pretende otorgar las prioridades a quienes realmente corresponden.

Los estrategas y conductores políticos asumieron el concepto seguridad como algo inherente al pólemos, es decir, a la guerra y sus efectos colaterales; por esta razón, ellos construyeron una catedral del saber a la que no tuvieron acceso quienes no estaban inmersos en los oficios de la 
estrategia. Por fortuna, el nuevo siglo ha permitido ampliar la función de seguridad, al cubrimiento de las más elementales necesidades humanas, así como a la defensa de todos los derechos.

La consagración de un derecho fundamental al agua en el derecho internacional es indispensable para mejorar la satisfacción general de esta necesidad básica. Su denegación generalizada afecta gravemente el disfrute de derechos fundamentales como el derecho a la vida, alimentación, salud, vivienda o educación. El establecimiento de reglas claras, expresadas en términos de derechos y obligaciones de los Estados, los particulares y las organizaciones internacionales, mejoraría su posición en el amplio panorama de derechos humanos reconocidos internacionalmente.

Un futuro tratado sobre el derecho fundamental al agua incorporaría la creación de una Agencia Internacional del Agua con capacidad de superar las graves deficiencias actuales de los mecanismos de protección internacional del conjunto de los derechos económicos sociales y culturales. Esta organización debería estar abierta a una participación plural de los Estados, organizaciones internacionales, organizaciones no gubernamentales y empresas multinacionales.

No hay duda de que avanzar decididamente en el cumplimiento de los Objetivos del Milenio pasa por la garantía del derecho al agua para toda la población. En la mente de los agentes internacionales ha germinado el reconocimiento de la existencia de este derecho y la voluntad de definir su alcance y los medios idóneos para su protección. Los contornos generales de este derecho fundamental ya han sido perfilados a través de los trabajos de diferentes organizaciones hacia un derecho humano fundamental al agua en el derecho internacional.
América Latina, poseedora de la mayor biodiversidad sobre el planeta, afronta problemas de pobreza que no se justifican y que impiden su desarrollo en condiciones sustentables en un mundo globalizado en el que teóricamente, la oferta y la demanda deciden los movimientos del mercado con miras a mejorar la calidad de vida de más de 800 millones de habitantes. Los recursos naturales han pasado a ser en el nuevo siglo los productos más valiosos para continuar en la carrera del desarrollo tecnológico, supuestamente con la intención de buscar el bien común.

Las políticas públicas en la región con respecto a la distribución del agua muestran desinterés por parte de la clase dirigente, aumentando la brecha entre ricos y pobres y generando riesgos para la salud y la vida de sus habitantes. El subdesarrollo en gran parte está relacionado con la ineficiencia en la prestación de los servicios públicos y mientras las políticas públicas no se orienten a reducir la desigualdad económica, el tercermundismo seguirá siendo una realidad.

En Colombia, al igual que en los países pobres, la existencia de recursos naturales abundantes en nada beneficia a sus ciudadanos y por el contrario, esta nación subsiste en la condición de proveedora y exportadora de materias primas. Considerada una de las mayores productoras de agua, afronta problemas de contaminación, ineficiencia en el cubrimiento y mala calidad para garantizar la vida y salud de sus ciudadanos.

La conversión de los páramos en unidades de producción agrícola y ganadera y la deforestación creciente explican otra compleja realidad, que periódicamente genera emergencias naturales que afectan a los grupos humanos más vulnerables. No se han resuelto los graves problemas derivados del manejo contaminante del agua provocados por la actividad de extracción de crudo y manejo de residuos en regiones petroleras. Una de las tensiones 
fundamentales de la coyuntura actual es la intención de permitir las actividades mineras, consumidoras de gran cantidad de agua. Este es un tema crucial, pues el incremento exagerado de la industria minera, provocaría permanentes conflictos por la disponibilidad del agua y contaminaría el líquido vital, causando afectaciones a la soberanía alimentaria. Existen estudios que demuestran que la contaminación provocada por la minería existente se extiende peligrosamente por el territorio nacional afectando incluso extensas zonas fronterizas, asunto que tiene estrecha relación con el futuro manejo de las relaciones internacionales.

Teniendo en cuenta la situación actual del país y las tendencias en relación con la oferta y la demanda de agua, las regiones Andina y Caribe son las más vulnerables. La tendencia es al incremento de la vulnerabilidad actual y a la aparición de nuevas áreas con índices críticos, por cuanto los procesos de deterioro por contaminación o disminución de la oferta por afectación del ciclo hídrico y un aumento constante en la demanda, se mantendrán en el mediano plazo.

Sobre la base del modelo actual de oferta y demanda de alimentos y agua, si persisten las actuales políticas, a los productores agrícolas les va a resultar realmente difícil satisfacer las necesidades alimentarias. El efecto más fuerte lo sufrirán los más pobres. Si se siguen desatendiendo las inversiones y las políticas vinculadas al agua, se generará una grave crisis en el suministro, que a su vez llevará a una crisis en el suministro de alimentos. De nada sirve tener políticas, técnicas y tecnologías para ahorrar agua si las mismas no se llevan a la práctica. Cuando los incentivos y las instituciones no son apropiados, con frecuencia impiden un aprovechamiento eficaz del agua.

Es urgente la articulación institucional para la participación cabal de todos los actores implicados en la planificación y gestión del acceso al agua. El reto más importante del Estado sería el de llevar a cabo funciones integrales de garantía del derecho al agua: planificación, financiación, gestión, previsión contable y tutela jurídica del derecho al agua. Las causas más importantes de la crisis del agua en la actualidad no derivan de su escasez sino de la pobreza, el subdesarrollo, las relaciones de poder y, con mayor peso, de las políticas nacionales erradas de gestión del agua potable que agravan el problema de su escasez. La negación masiva del derecho al agua cumple hoy un papel simbólico, y permite el juicio más severo a la humanidad, y en especial, a sus dirigentes políticos.

\section{Referencias}

Aguilar Villanueva, L.F. (1992). El Estudio de las Políticas Públicas. México: Ed. Miguel Ángel Porrúa.

Aguilera Peralta, G. (1994). Seguridad, Función Militar y Democracia. Guatemala: Editorial Impreofset.

Barnett, J. (1997). Environmental Security: Now What? Seminar, Department of International Relations, Keele University.

Bertrand, Badie \& Smouts, M.C. (2000). Los operadores del cambio de la política mundial ( $2^{\mathrm{a}}$ ed.). México: Publicaciones Cruz.

Cabanellas de Torres, G. (1983). Diccionario Militar (Aeronáutico, Navaly Terrestre) (Tomo VI). Buenos Aires: Editorial Claridad.

Cadena Montenegro, J. L. (1999). Propuesta de evaluación de la eficiencia y eficacia del Ejército de Colombia. Tesis de grado para obtener el título de Magíster en Ciencia Política, Universidad de Los Andes, Bogotá. 
Cadena Montenegro, J. L. (2002). La geografia y el poder. Territorialización del poder en Colombia. De Marquetalia al Caguán. Tesis de grado para obtener el título de Magíster en Geografia, Universidad Pedagógica Tecnológica de Colombia - IGAC. Bogotá.

Carbonell Sánchez, M. (2000). Los derechos de seguridad jurídica. En Los derechos fundamentales en México.

Castaño Uribe, C. (2002). Colombia alto andina y la significacia ambiental del bioma páramo en el contexto de los Andes tropicales: una aproximación a los efectos futuros por el cambio climático global. Bogotá.

Castaño, C. Los páramos en el filo de la navaja. Recuperado el 6 de junio de 2011 desde http:/ / www.biodiversityreporting.org/article.sub?docId=694\&c=Colombia\&cRe $\mathrm{f}=$ Colombia\&year $=2003 \&$ date $=$ February $\% 202003$

Cope, J.A. (1997). En busca de la convergencia: las relaciones militares entre México y Estados Unidos en el umbral del siglo $X X I$.

Defensoría del Pueblo. (2010). Decimoséptimo informe del defensor del pueblo al Congreso de la República. Bogotá: Defensoría del Pueblo.

Departamento Nacional de Planeación. www. Dnp. Gov. co. consultado el 16 de mayo de 2011.

Farro, M. E. (2008). El agua como derecho humano. El caso de América Latina. El agua, derecho humano y raiz de conflictos.

Foros México. (1998-2007). recuperado el 10 de enero de 2011 desdehttp://www.seguridadpublica.com/seguridad-cientifica-world-travel-network-online.php
Giraldo, N. C. (2008). Agua para consumo doméstico en Colombia. Costos y regulación tarifaria. Gestión y ambiente.

Gleditsch Nilsk, P. (1998). Conflictos Medioambientales. En Seguridad y Medio Ambiente en el Mediterráneo. Berlin: Springer.

Lorino Philippe. (1993). El Control de Gestión Estratégico. Barcelona: Editorial Maracombo.

Meny, Y. y Thoenig, J.C. (1992). "Las Políticas Públicas y Teorías del Estado". En Las Políticas Públicas. Barcelona: Ariel.

Ministerio de Ambiente, Vivienda y Desarrollo Territorial. (2002). Congreso Mundial de Páramos (Tomo II). Boyacá, Colombia: Corporación Autónoma Regional de Cundinamarca, Instituto de Hidrología, Meteorología y Estudios Ambientales \& Conservación Internacional.

Murray, D. J. \& Viotti, P. R. (1994). The Defense Policies of Nations (A Comparative Study) (3rd ed.). Baltimore and London: The Johns Hopkins University Press.

Ortiz Navarrete, J. (2003). La doctrina de la seguridad humana en la política exterior canadiense. La contribución de Lloyd Axworthy al estudio de la política mundial. Revista Cidofb d'afers internacionals, 60.

Pereira, J. P. (2005). Seguridad Humana. Recuperado el 9 de marzo de 2011 desdehttp:/ / www.tdr.cesca.es/tesis_ uab/available/tdx-0620106- 153920/jcfplde1.pdf

Rico, J. M. (1997). Fusticia Penal y Transición Democrática en América Latina. México: Siglo XXI Editores. 


\section{Čír'́rế 19}

Sloterdijk, P. (2003). Temblores de Aire. En las fuentes del terror. Valencia: Pre-textos.

Taylor, P. (1994). Geografía Política. Madrid: Trama.
Terry Lynn, K. and Schmitter, P. (1991). "Modes of Transition and Types of democracy in Latin American, Southern and Eastern Europe". International Social Science fournal, 2, (XLIII). 